\title{
Study on Distribution Reliability with Parallel and On-site Distributed Generation Considering Protection Miscoordination and Tie Line
}

\author{
Surachai Chaitusaney Student Member (The University of Tokyo, surachai@syl.t.u-tokyo.ac.jp) \\ Akihiko Yokoyama Member (The University of Tokyo, yokoyama@syl.t.u-tokyo.ac.jp)
}

Keywords: backup generation, contingency enumeration, distributed generation, distribution system, protection coordination, reliability

Distributed Generation (DG) is currently promoted not only for its commercial purpose, but also for its power quality improving ability and environment friendly attribute. Regarding power quality, DG can be applied as backup generation when the main supply from the upstream side is interrupted. As backup generation, DG is supposed to improve the system reliability if the related concerns are deliberately considered and the solutions are strictly implemented. For example, the existing protection coordination in the system must not be jeopardized from the installation of DG. This is because the loss of protection coordination can deteriorate distribution reliability.

This paper assumes that all prerequisite requirements of DG installation are satisfied, except for the problem of protection coordination. This is to concentrate on the effect of DG on the loss of protection coordination, especially the problem of recloser-fuse miscoordination that can severely affect the system reliability. The contribution of DG may interfere the existing recloser-fuse coordination with the contribution in fault current, and change the sequence of protective operation. As the second problem, the installation of DG can also bring about the miscoordination between breaker and breaker that impact distribution reliability more in term of interruption rate. Although the risk of DG continuing to operate and contribute in fault current is low, it is not zero. Furthermore, it cannot be guaranteed that DG will be disconnected faster than system protective devices, which usually operate within only few cycles. Fig. 1 illustrates a sample typical coordination of breaker, recloser, and lateral fuse. Based on the coordination setting, the threshold size of DG beyond which causes protection miscoordination is calculated. Since DG is categorized typically into three types, i.e. synchronous, induction, and inverter-type generators, the effect of this paper proposes a model of DG fault current that is probabilistically based on the composition of these various DG types and their output behaviors. In addition, DG may have less advantage to distribution reliability if the connecting feeder is tied with another feeder or an adjacent substation. However, the numerical results show that a tie line is overcome by DG in some cases, since it cannot continuously supply electricity to the load that is located behind the lateral fault. In contrary, on-site DG, also located behind the lateral fault, can continuously supply this load.

From the numerical examples, it can be concluded for the test system that the system reliability is certainly improved with DG installation while recloser-fuse miscoordination is neglected. In contrast, the system SAIFI becomes severely worse when

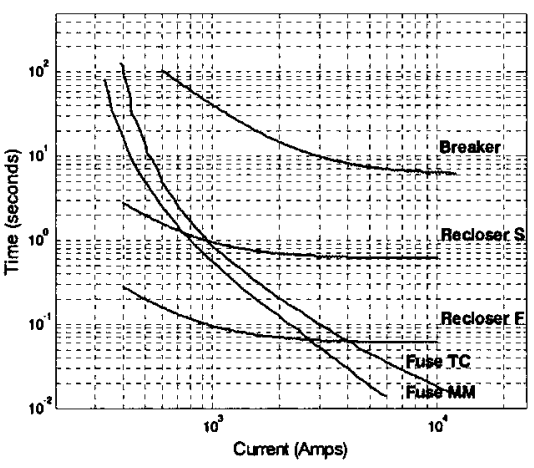

Fig. 1. Typical coordination of protective devices

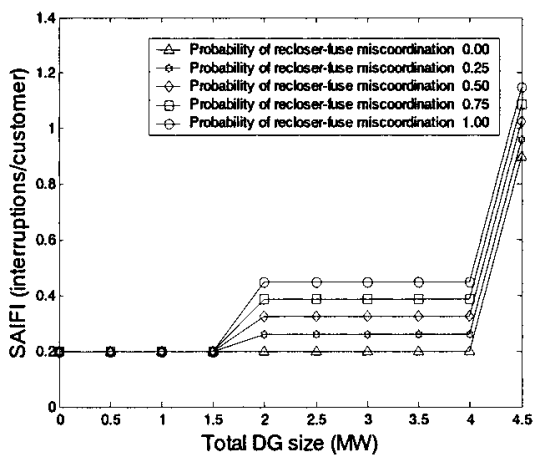

Fig. 2. SAIFI of feeder 1 associated with change of total DG capacity considering the impact of breaker-breaker miscoordination

recloser-fuse miscoordination is taken into account, whereas the system SAIDI and ENS can still be improved. These confirm the fact that DG has both pros and cons to the system reliability. Besides, sensitivity study of the system reliability is conducted. It can be seen from the results that the size of DG can improve the system reliability in terms of SAIDI and ENS until a value of DG capacity. If the size of DG is increased to be over the threshold capacity of DG, the SAIDI and ENS will become worse. Fig. 2 demonstrates an example of the sensitivity study that takes into account both recloser-fuse and break-breaker miscoordination. This paper also describes the importance of the location that DG is installed. The numerical examples clearly show the advantage of DG even the system has tie lines. 


\title{
Study on Distribution Reliability with Parallel and On-site Distributed Generation Considering Protection Miscoordination and Tie Line
}

\author{
Surachai Chaitusaney* Student Member \\ Akihiko Yokoyama* Member
}

\begin{abstract}
In distribution system, Distributed Generation (DG) is expected to improve the system reliability as its backup generation. However, DG contribution in fault current may cause the loss of the existing protection coordination, e.g. recloser-fuse coordination and breaker-breaker coordination. This problem can drastically deteriorate the system reliability, and it is more serious and complicated when there are several DG sources in the system. Hence, the above conflict in reliability aspect unavoidably needs a detailed investigation before the installation or enhancement of DG is done. The model of composite DG fault current is proposed to find the threshold beyond which existing protection coordination is lost. Cases of protection miscoordination are described, together with their consequences. Since a distribution system may be tied with another system, the issues of tie line and on-site DG are integrated into this study. Reliability indices are evaluated and compared in the distribution reliability test system RBTS Bus 2.
\end{abstract}

Keywords: backup generation, contingency enumeration, distributed generation, distribution system, protection coordination, reliability

\section{Introduction}

Distributed Generation (DG) is attracting more and more attention in recent years. DG is promoted not only for its commercial purpose, but also for its power quality improving ability and environment friendly attribute. Regarding power quality, DG can be applied as backup generation when the main supply from the upstream side is interrupted ${ }^{(1)-(3)}$. Without the main electricity source, isolated system is formed and obtains electricity supply from the DG located in the isolated area. As backup generation, DG is supposed to improve the system reliability if the related concerns are deliberately considered and the solutions are strictly implemented. For example, the isolated area must be able to maintain its own voltage and frequency within a range of the specified standard. In addition, the existing protection coordination in the system must not be jeopardized from the installation of DG. DG interface control, of both rotating and inverter sources, is responsible for the control of voltage and frequency. This can be achieved by real and reactive power sharing of DG sources to balance the scheduled load ${ }^{(4)(5)}$. On the subject of protection coordination, a number of preventive solutions have been proposed in addition to disconnection of DG, e.g. optimal sizes of DG sources and anti-islanding protection scheme ${ }^{(6)-(9)}$.

This paper assumes that all prerequisite requirements of DG installation are satisfied, except for the problem of protection coordination. This is to concentrate on the effect of DG on the loss of protection coordination, especially the problem of recloser-fuse miscoordination that significantly impacts the reliability of typical radial distribution system ${ }^{(10)}$.

\footnotetext{
* Department of Electrical Engineering, The University of Tokyo

7-3-1, Hongo, Bunkyo-ku, Tokyo 113-8656
}

The contribution of DG may interfere the existing recloserfuse coordination with the change in fault current. In practice, recloser should discriminate temporary faults, occurring mostly in distribution system, and operate faster than a lateral fuse. However, a lateral fuse may operate faster than the recloser with the additional fault current from DG. This is because protective devices are typically based on inverse-time overcurrent characteristic. The higher the fault current is, the faster the protective device in charge will operate. With the fuse operation, temporary faults will turn to be permanent. As the second problem, the installation of DG also brings about the miscoordination between breaker and breaker. It is true that such kind of the second problem rarely happens, but its impact is more adverse to distribution reliability. This is because it does cause wide area of electricity interruption. Although the risk of DG continuing to operate and contribute in fault current is low, it is not zero. Furthermore, it cannot be guaranteed that all DG sources will be disconnected faster than system protective devices, which usually operate within only few cycles ${ }^{(11)}$. Since DG is typically categorized into three types, i.e. synchronous, induction, and invertertype generators, the different effects of DG fault current is probabilistically modeled with the composition and behaviors of these various DG types.

In addition, DG, installed parallel at the main feeder, may have less advantage to distribution reliability if the main feeder is tied with another feeder or an adjacent substation. Tie line can fully provide backup generation to its connecting feeder. However, tie line is overcome by DG in some cases, since it cannot continuously supply electricity to the load that is located behind the lateral fault. In contrary, on-site DG, also located behind the lateral fault, can continuously supply this load. This issue is also integrated into the numerical study. Two load point indices are evaluated: SAIFI (System 
Average Interruption Frequency Index) and SAIDI (System Average Interruption Duration Index). As regards energy index, ENS (Energy Not Supplied) is computed.

To begin with, section 2 provides a brief principle of backup generation. Operating function of protective devices are mentioned in section 3 together with the cases of protection miscoordination. A model of DG fault current is proposed in section 4 for a composite lumped DG source. Section 5 comprehensively describes the effect of recloser-fuse miscoordination. Section 6 addresses the study cases that are extensively investigated later in section 7 , the numerical examples. Lastly, the conclusion is drawn in section 8 .

\section{Backup Generation}

The concept of system isolation is not new for power engineering ${ }^{(12)}$. In addition, it seems to be less useful if the electric power flows uni-directionally downstream from the substation in radial distribution system. However, the isolation is much beneficial when DG is present, especially when DG with enough supplying capacity is located at the end of feeder. In this paper, backup generation from DG means the generation supplied by DG for the isolated area. This DG can be connected either parallel at the main distribution feeder or the site of loads (on-site DG). This is because DG can upstream supply loads whose locations are behind the failed and disconnected component. These loads can be supplied without waiting until the repair is done (repair time), but just wait for the isolation process (switching time). This certainly increases the reliability of the isolated area.

\section{Protection Coordination}

Unlike the problem of recloser-fuse miscoordination, the problem of breaker-breaker miscoordination rarely takes place in typical radial distribution system. Moreover, it is less complicated than the problem of recloser-fuse miscoordination. As a result, this paper will concentrate more on the recloser-fuse miscoordination. To begin with, the functions and mathematic characteristics of typical protective devices are briefly described in section 3.1. Then, the description of breaker-breaker miscoordination is presented in section 3.2. Lastly, the problem of recloser-fuse miscoordination is investigated in section 3.3 and 3.4.

3.1 Functions and Characteristics of Protective Devices In a typical distribution system, all system loads are supplied from a bulk supplying point, distribution substation, connected to the transmission system. Then, the electricity is transmitted to the distribution system via substation transformers. The electricity is transmitted to loads through normally radial distribution feeders and then through lateral feeders and lateral transformers. Showing protective devices, Fig. 1 illustrates a sample of typical radial distribution feeder. To protect system components and satisfy safety purpose, the protective devices must be installed along the main and lateral feeders. In general, circuit breaker (CB) and automatic circuit recloser (ACR) are designed to protect the system by disconnecting the circuit at the beginning and the middle as their locations on the main feeder. Besides, lateral fuses are placed at the lateral feeders and are responsible for the protection of these lateral circuits.

Basically, there is not any definite protection coordination

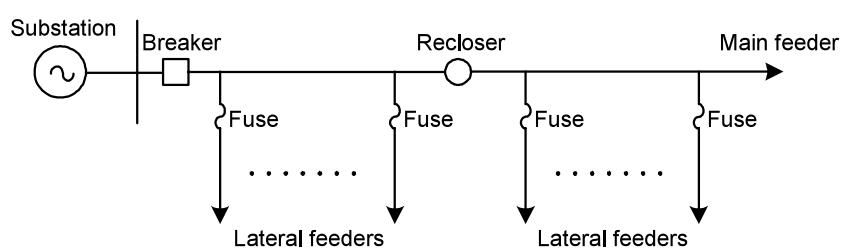

Fig. 1. Typical radial distribution feeder

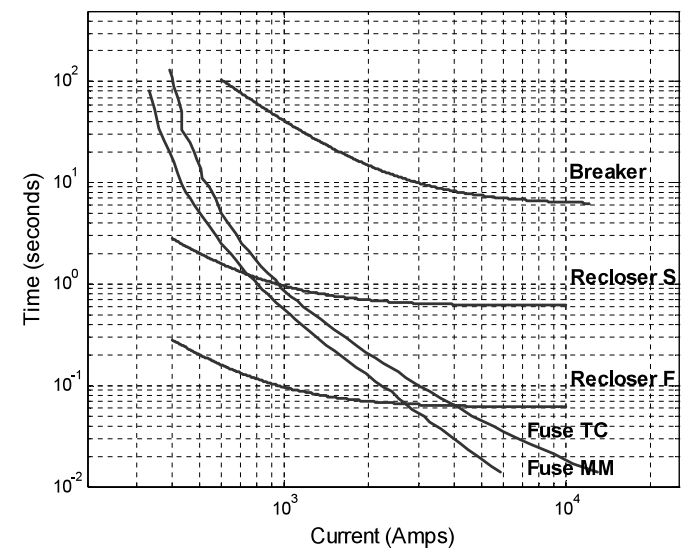

Fig. 2. Typical coordination of breaker, recloser, and fuse

scheme. The coordination scheme is normally determined according to individual specific topology of a distribution system, as well as various desired behaviors. As a typical distribution feeder in Fig. 1, the traditional protection coordination could be shown in Fig. $2^{(8)(9)}$. This is a general coordination of circuit breaker, recloser, and a lateral fuse behind the recloser. A lateral fuse is responsible for the permanent fault that occurs in part of lateral feeder. However, if the fault is temporary or that fault occurs on the main feeder behind the recloser, the recloser will be instead the device that trips the circuit in order to confine the interrupted area. The operation of the recloser also includes the function of backup protection when a fuse fails to be blown up. For the breaker, it is responsible for the fault that occurs in front of the recloser. In addition, the breaker is used as the whole backup protection for the whole feeder when both the recloser and lateral fuses fail in their function. Note that the descriptions TC and MM of fuse mean total clearing and minimum melting characteristics respectively, and the descriptions $\mathrm{S}$ and $\mathrm{F}$ of recloser mean slow and fast operation modes respectively.

For circuit breaker and recloser, they are normally equipped with inverse-time overcurrent trip devices. The general characteristics of such devices can be shown as the following equation $^{(13)}$.

$$
t(I)=\frac{A}{M^{P}-1}+B
$$

where

$t$ : operating time of inverse-time overcurrent device,

$I$ : fault current seen by the device,

$M$ : ratio of $I / I_{\text {pickup }}\left(I_{\text {pickup }}\right.$ is relay current set point),

$A, B, p$ : constants for selected curve characteristics.

Likewise, fuses also have such inverse-time overcurrent characteristic. The straight line $I^{2} t \log -\log$ plot is usually expressed for the minimum melting and total clearing times for 


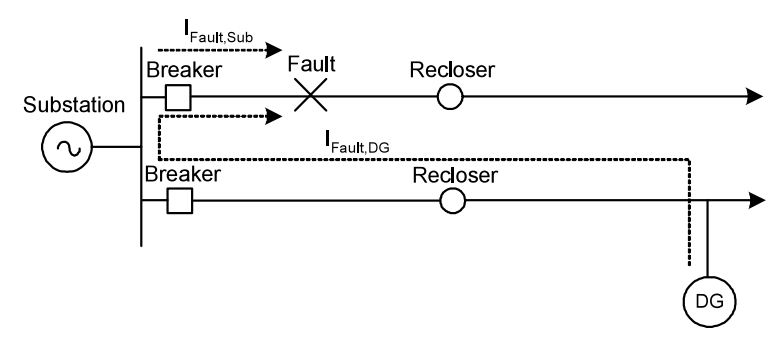

Fig. 3. Problem of breaker-breaker miscoordination

fuses. To be used in the protection setting, the fuse characteristic on the log-log curve is better to be mathematically approximated by the second order polynomial function. However, the interested range of the curve approaches a straight line. Moreover, a linear equation can be simply applied to reduce the calculation task. The general equation describing the fuse characteristic curve can be expressed as Eq. (2).

$$
\log (t)=a \cdot \log (I)+b \cdots \cdots \cdots \cdots \cdots \cdots \cdots(2)
$$

where $t$ and $I$ are the associated time and current, and the coefficients $a$ and $b$ can be known from the curve fitting.

\subsection{Problem of Breaker-breaker Miscoordination}

Figure 3 shows a distribution system comprising two radial feeders. When a fault occurs at the upper feeder, the operating device should be the devices located in that feeder, e.g. circuit breaker. Nevertheless, the circuit breaker at the healthy feeder, the lower feeder in this example, may operate due to the fault current from DG with large capacity. This may cause unreasonable electricity interruption on this healthy feeder. The possibility of occurrence is higher when the size of DG is very large that yields a very high fault current. However, if the size of DG is not so large, it seems less severe in the case where both faulted and healthy feeders have same or similar circuit breakers and setting. This is because the operating time of both circuit breakers will be different. Regardless of fault current form load, the fault current seen by the circuit breaker in the healthy feeder is only from DG, whereas the current seen by the circuit breaker in the faulted feeder is from both utility substation and DG. As a result, the operating time of the circuit breaker in the faulted feeder will be faster and the operating sequence of both circuit breakers can be discriminated.

3.3 Problem of Recloser-fuse Miscoordination With the contribution of DG fault current, the coordination of recloser and fuse may be interfered, and the system reliability may be affected. As shown in Fig. 2, the principle of recloserfuse coordination is extended in this section. When a fault occurs at the lateral feeder, the recloser at fast mode should operate first to discriminate for temporary faults, occurring mostly 70 to 80 percent in distribution system ${ }^{(14)(15)}$. If the fault still exists, lateral fuse will be blown up and cause a permanent electricity interruption. However, if fuse fails to operate in this stage, recloser at slow mode can act as a backup protection later. As an example of the above problem, a situation for recloser-fuse miscoordination is set up as follows. A DG source is located at the end of feeder and a fault occurs at a lateral feeder behind the recloser. To obtain the proper sequential coordination, the fault current must comply with the minimum and maximum current illustrated in Fig. 4. In this case, the fault current flowing through the recloser is different

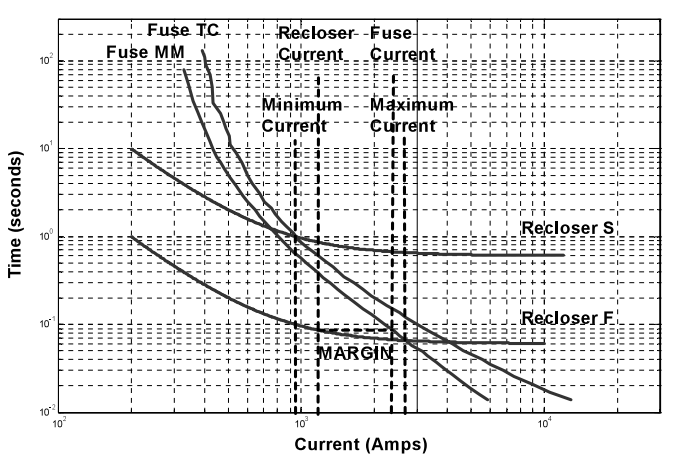

Fig. 4. Sample coordination between recloser and fuse

from the fault current flowing through the fuse. It is obvious that the fault current seen by the fuse is higher than the fault current seen by the recloser. The fault current seen by recloser is the portion from only the substation, whereas the fault current seen by the fuse is the portions from both the substation and the DG. With the different fault current seen by the two devices, fuse blowing may occur meaninglessly. Since the occurrence rate of temporary faults is very high in distribution system, recloser-fuse coordination is considered critical for the distribution reliability, and must be taken into account when the reliability worth of DG is evaluated.

Therefore, there should be a margin of the fault current for the proper coordination, considering the presence of DG. From Fig. 4, the relation of the fault current from utility substation and the maximum or margin fault current from DG can be written as Eq. (3).

$$
I_{\text {fuse,margin }}=I_{S}+I_{\text {margin }}
$$

where

$I_{S}$ : fault current from utility substation,

$I_{\text {margin }}$ : margin for DG fault current,

$I_{\text {fuse,margin }}$ : current seen by fuse with $I_{\text {margin }}$ from

DG.

To ensure that the recloser $\mathrm{F}$ will operate before fuse MM, the fault current from DG must be lower than $I_{\text {margin }}$. Hence, the following equation can be expressed.

$$
I_{D G}<I_{\text {margin }}
$$

where $I_{D G}$ is the fault current from DG.

From Eqs. (3) and (4), the DG fault current can be calculated as shown in Eq. (5). Since the DG fault current is higher when the size of DG becomes larger, this relation will be used later to find the threshold of the miscoordination when the size of DG is increased. The detailed calculation for the margin can be carried out mathematically by using the equations of recloser and fuse characteristics as proposed in the Refs. (7) and (8).

$$
I_{D G}<I_{\text {fuse,margin }}-I_{S}
$$

3.4 Cases of Recloser-fuse Miscoordination The above subsection shows an example that lateral fuses may functionally change temporary faults to permanent interruption if the size of DG is excessively large. Before considering the effect of miscoordination on the system reliability, the thorough investigation for all possible cases of miscoordination should be clarified. From Fig. 5, assuming that only one 


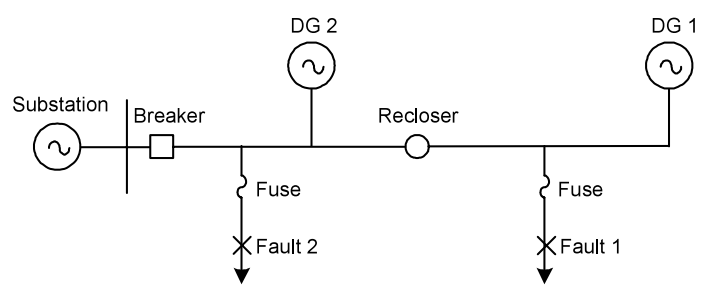

Fig. 5. Sample typical distribution system

Table 1. Description of fault current seen by recloser and fuse

\begin{tabular}{|c|c|c|c|}
\hline Case & DG source & Fault position & Description \\
\hline 1 & DG 1 & Fault 1 & $I_{R}=I_{S}$ and $I_{F}=I_{S}+I_{D G}$ \\
\hline 2 & DG 1 & Fault 2 & $I_{R}=I_{D G}$ and $I_{F}=I_{S}+I_{D G}$ \\
\hline 3 & DG 2 & Fault 1 & $I_{R}=I_{F}=I_{S}+I_{D G}$ \\
\hline 4 & DG 2 & Fault 2 & No $I_{R}$ and $I_{F}=I_{S}+I_{D G}$ \\
\hline
\end{tabular}

DG source is installed in each case, there are four cases as shown in Table 1 . The notations $I_{R}$ and $I_{F}$ mean fault current seen by recloser and fuse respectively, and $I_{S}$ and $I_{D G}$ mean fault current flowing from utility substation and DG source respectively.

In case 1, fault current seen by the recloser equals to the fault current flowing from the substation, and fault current seen by the fuse equals to the summation of both fault current from the substation and the DG. With this situation, it is possible that the miscoordination of recloser and fuse will happen. It means that the problem will occur whenever both the DG source and the fault are located behind the recloser. In contrast, the fuse should operate faster in case 2. However, it is possible that the recloser at fast mode will operate faster and meaninglessly cause the electricity interruption at the rear circuit. Since the rear circuit however can be automatically restored within only few cycles after the fuse has operated, it brings about only a momentary electricity interruption, which may be negligible. In case 3 , the fault current flows through the recloser and the fuse is same. This seems that recloser and fuses can coordinate properly. However, the DG fault current may cause the total fault current to exceed the maximum current shown in Fig. 4. Consequently, this can cause the fuse to operate before the recloser at fast mode. On the contrary, recloser-fuse miscoordination never occurs in case 4 . In this case, the fault current from both the substation and the DG flow to fuse directly and the recloser detects nothing. Thus, only the loss of coordination from cases 1 and 3 will be considered in the study.

\section{Model of DG Fault Current}

In this paper, power generation from DG at each bus is considered as a lumped source of several DG units. For example, it is possible that the lumped DG source is composed of synchronous, induction, and inverter-type generators. These three generation types typically cause different characteristics of fault current, i.e. percent of rated output and decaying duration as shown in Table $2^{(6)(16)}$. With the known tripping time of the protective device in charge, the fault current can be approximated in percent of the rated output current of generator type $j^{t h}$, denoted here as $F_{j}$. To calculate the fault current from each type of generator, the operating behavior
Table 2. Typical characteristics of fault current

\begin{tabular}{|l|l|}
\hline \multicolumn{1}{|c|}{ Type of generation } & $\begin{array}{c}\text { Fault current into faulted bus as percent of } \\
\text { rated output current }\end{array}$ \\
\hline $\begin{array}{l}\text { Separately excited } \\
\text { synchronous generator }\end{array}$ & $\begin{array}{l}500-1000 \% \text { for the first few cycles and } \\
\text { decaying to } 200-400 \%\end{array}$ \\
\hline $\begin{array}{l}\text { Induction generator or self } \\
\text { excited synchronous } \\
\text { generator }\end{array}$ & $\begin{array}{l}500-1000 \% \text { for first few cycles and decaying to } \\
\text { a negligible amount within } 10 \text { cycles }\end{array}$ \\
\hline Inverter & $\begin{array}{l}100-400 \% \text { and may even be less than } 100 \% \text { for } \\
\text { some inverters; feeding duration depends on } \\
\text { controller technologies and settings }\end{array}$ \\
\hline
\end{tabular}

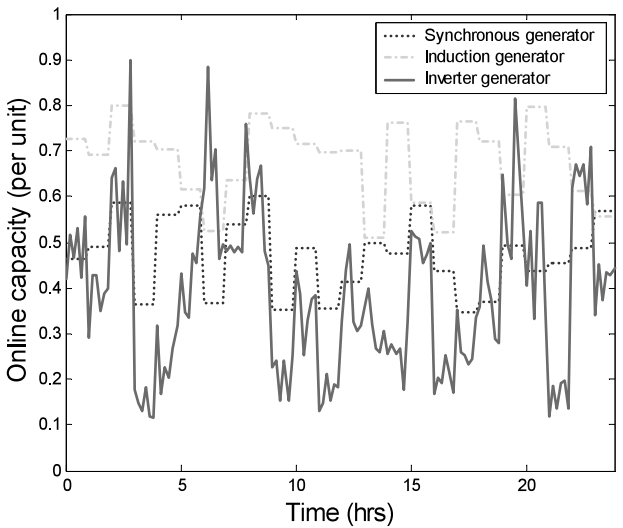

Fig. 6. Sample operating behavior of each generator type in 24 hours

of each type of generator must be known. For each generator type, Fig. 6 shows sample generation outputs of the total installed capacity. Therefore, the probability of online generators that are prompt to feed their fault current to the system is computed, and this probability is denoted as $P_{j}$ for generator type $j^{t h}$. As a result, the expected total fault current, $I_{F, t o t a l}$, can be approximately calculated for each lumped DG source as shown in Eq. (6).

$$
I_{F, \text { total }}=\sum_{j=1}^{N_{j}}\left(P_{j} \times F_{j} \times I_{\text {rated }, j}\right) .
$$

where $I_{\text {rated }, j}$ is the rated output current from generator type $j^{\text {th }}$ of the lumped DG source and $N_{j}$ is three in this context according to the number of typical types of DG generation.

\section{Effect of Recloser-fuse Miscoordination}

As aforementioned, miscoordination of recloser-fuse can deteriorate the system reliability by changing the interruption duration from temporary faults to be permanent interruption. In this paper, faults lasting less than few seconds are classified as the temporary faults. The related reliability statistics are first presented in section 5.1. The calculation for the change of interruption duration is then described in section 5.2.

5.1 Permanent and Temporary Faults In general, load point indices are used to evaluate distribution reliability ${ }^{(12)}$. For the system component $i^{\text {th }}$, three reliability statistics are used to evaluate the system reliability, i.e. $\lambda_{i}$ (average failure rate, f/yr), $r_{i}$ (average outage time, hours), and $U_{i}$ (average annual outage time, hours/yr). In this frame work, $\lambda_{i}$ is assumed to result only from electricity faults, regardless 
of thermal limit, planned outage, and etc. As mentioned in section 2, each system component will be interrupted as long as repair or switching times, depending on the location of the considered component itself and the location of the failed component, as well as the type of fault. Certainly, these interruption durations stipulate the outage duration for the load points connecting to the interrupted component. Hence, the outage information of load points can be directly calculated from the reliability statistics of system components. Since this paper considers temporary faults in addition to permanent faults, each of the three reliability statistics $\left(\lambda_{i}, r_{i}, U_{i}\right)$ should be divided into two groups, i.e. permanent and temporary. To begin with, the average failure rate can be written as Eq. (7).

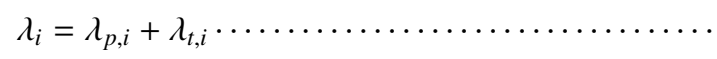

where $\lambda_{p, i}$ and $\lambda_{t, i}$ are the permanent and temporary average failure rates respectively. Both of them give the different average outage times as $r_{p, i}$ and $r_{t, i}$ for the permanent and temporary faults, respectively. In case of permanent faults, $r_{p, i}$ is the repair time described in section 2, while $r_{t, i}$ is just few seconds in case of temporary fault. As a result, the average annual outage time for both types of faults can be calculated as the following equations.

$$
\begin{aligned}
& U_{p, i}=\lambda_{p, i} \times r_{p, i} \ldots \ldots \ldots \ldots \ldots \ldots \ldots \ldots \ldots \ldots \ldots \ldots \ldots \ldots \ldots \ldots \ldots \ldots \ldots \ldots \ldots \\
& U_{t, i}=\lambda_{t, i} \times r_{t, i} \ldots \ldots \ldots \ldots \ldots \ldots \ldots \ldots
\end{aligned}
$$

Lastly, the total average annual outage time and average outage time can be written as Eqs. (10) and (11).

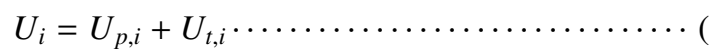

$$
\begin{aligned}
& r_{i}=U_{i} / \lambda_{i} \ldots \ldots \ldots \ldots \ldots \ldots \ldots \ldots \ldots \ldots \ldots \ldots \ldots \ldots \ldots \ldots \ldots
\end{aligned}
$$

Note that the average outage time of temporary faults, $r_{t, i}$, is very short. Without the change of interruption duration, Eqs. (7)-(11) can be simply calculated by only the terms of permanent faults.

5.2 Change of Interruption Duration The general description in section 5.1 is for the proper coordination of all protective devices. However, recloser-fuse miscoordination will change temporary faults to be permanent interruption for some affected system components and load points. For instance, lateral feeders and transformers may be interrupted as long as the repair time of fuse, used to replace the fuse blown from the miscoordination. Hence, the above calculation of $\lambda_{i}, r_{i}$, and $U_{i}$ is invalid for the change of interruption duration. The average failure rate is still same as Eq. (7), but the average interruption time for temporary faults will be changed to be the repair time of fuse $r_{f, i}$.

Assuming that the composition of various DG sources at the connecting point is known, the probabilistic characteristic of lumped DG sources can be modeled as presented in section 4. With this uncertainty of DG composition, the fault current from DG sources will affect the recloser-fuse miscoordination in probabilistic manner. Therefore, if the probability of miscoordination, $p$, is given, the average annual outage time for temporary faults can be formulated as follows.

$$
U_{t, i}=\lambda_{t, i} \times\left((1-p) \times r_{t, i}+p \times r_{f, i}\right) \cdots \cdots \cdots \cdots
$$

However, the duration of $r_{t, i}$, is very short and negligible.
The equation can be rewritten as Eq. (13).

$$
U_{t, i}=\lambda_{t, i} \times\left(p \times r_{f, i}\right)
$$

Note that $r_{f, i}$ is definitely longer than few seconds. Hence, load will experience the longer interruption duration that is considered to be permanent.

\section{Study Algorithm}

To analyze the conflict between backup generation and the loss of protection coordination, four important cases of distribution system are analyzed as follows.

(1) No tie-line system without installation of DG

(2) No tie-line system with installation of parallel DG, but neglecting recloser-fuse miscoordination

(3) No tie-line system with installation of parallel DG, and considering the loss of protection coordination

(4) System with tie line and installation of on-site DG

6.1 Case (1) Case (1) is aimed at evaluating the normal reliability indices that will be used as a comparative base case. First, the N-1 contingency enumeration of system components is formulated to calculate the load point indices. The faulted component will be interrupted as its repair time, resulting in two groups of interrupted load points. The first group is the load points that directly connected to faulted component, and the second group is the load points that are located downstream the faulted component. Regarding the load points upstream the faulted component, they are interrupted as the switching time, and then return to get supplied from substation as the isolation is completely achieved. Hence, average outage time for permanent faults, $r_{p, i}$, will be substituted by switching time, $r_{s, i}$. Since temporary faults take time just a short period, the reliability statistics $\lambda_{t, i}, r_{t, i}$, and $U_{t, i}$ can be neglected at this stage. The load point indices, SAIFI and SAIDI, and ENS can be defined as the following equations ${ }^{(12)}$.

$$
\begin{aligned}
\text { SAIFI } & =\frac{\text { total number of customer interruptions }}{\text { total number of customers }} \\
& =\frac{\sum \lambda_{k} N_{k}}{\sum N_{k}} \ldots \ldots \ldots \ldots \ldots \ldots \ldots \ldots \ldots \\
\text { SAIDI } & =\frac{\text { sum of customer interruption durations }}{\text { total number of customers }} \\
& =\frac{\sum U_{k} N_{k}}{\sum N_{k}} \ldots \ldots \ldots \ldots \ldots \ldots \ldots \ldots \ldots \ldots \ldots \ldots \ldots \ldots
\end{aligned}
$$

The reliability statistics $\lambda_{k}$ and $U_{k}$ are the average failure rate and average annual outage time of the load point $k^{\text {th }}$, derived from the contingency enumeration. The customer information $N_{k}$ and $L_{a, k}$ are the number of customers and the average load connected to load point $k^{\text {th }}$.

6.2 Case (2) To obtain the ideally expected reliability improvement with large-capacity DG, the miscoordination is disregarded in this case. The DG sources are assumed to be connected parallel at the main feeder. Only the load points that directly connected to the faulted component 
will be interrupted in repair time. The rest of load points will be interrupted as the switching time of the faulted component since they can get supplied from either substation or DG after the faulted component is completely removed. As a result, switching time is used instead of repair time for the average outage time. Since recloser-fuse miscoordination is neglected in this case, the reliability statistics $\lambda_{t, i}, r_{t, i}$, and $U_{t, i}$ mentioned in section 5 can be neglected as same as case ( 1 ). Lastly, the reliability indices can be calculated as described in case (1).

6.3 Case (3) Case (3) explicitly shows the conflict of the reliability improvement from the backup generation and the reliability deterioration from the recloser-fuse miscoordination. Similarly to case (2), only the load points that directly connected to the faulted component will be interrupted with the repair time. The rest of load points will be interrupted with the switching time of the faulted component. Since recloser-fuse miscoordination is considered in this case, the reliability statistics of temporary faults, $\lambda_{t, i}, r_{t, i}$, and $U_{t, i}$ are necessarily taken into account. The reliability indices can be calculated as describe in case (1).

6.4 Case (4) This case is basically considered tie line as the main backup generation. Since tie line is normally applied at the end of feeder, it can be fully used to provide the backup generation for the whole long feeder. Consequently, there is no need to use DG to improve the system reliability. Without the installation of DG, recloser-fuse miscoordination will not occur. In stead of DG, the use of tie line however tends to cause the problem of voltage drop. The voltage profile may drastically drop at the interrupted feeder due to the long distance, including the length of adjacent feeder, the length of tie line, and the length of interrupted feeder itself. With tie line at the end of radial feeder, the role of DG as backup generation seems to be taken over. However, the faulted circuit behind these lateral fuses or breakers will be isolated, and inevitably cannot be supplied from the tie line. It is assumed that the Point of Common Coupling (PCC) is located behind lateral fuses or breakers as shown in Fig. $7^{(17)}$. As a result, the on-site DG behind the PCCs, unlike parallel DG at main feeder in cases (2) and (3), is still part of isolated circuit, and can provide continuous electricity supply. Therefore, reliability improvement can be achieved at the load of this local area. This means that DG behind PCCs is still beneficial to the system reliability. Nonetheless, if the size of DG is too large, DG may cause the loss of protection coordination when the fault position is somewhere else.

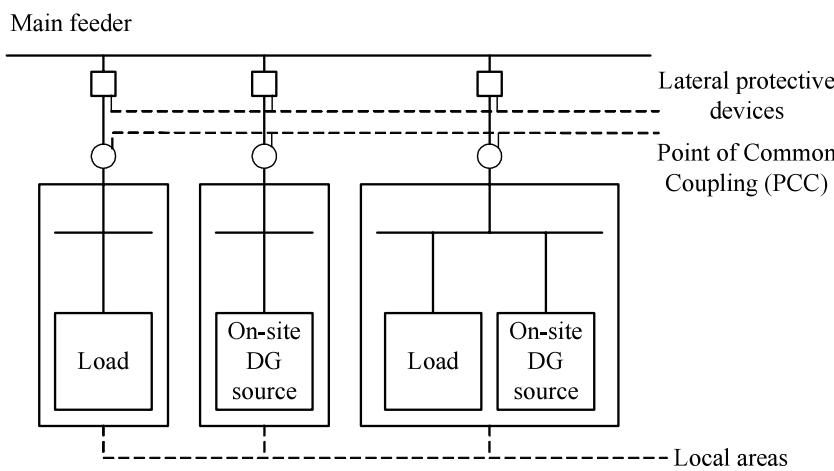

Fig. 7. Cases of load and DG installation behind PCCs
The reliability may be deteriorated in this situation. This is a problem of the overall evaluation of reliability indices that needs more intensive investigation.

\section{Numerical Examples}

The distribution reliability test system RBTS Bus 2, shown in Fig. 8, is used to study the distribution reliability conflict from DG installation ${ }^{(18)}$. The reliability statistics $\left(\lambda_{i}, r_{i}\right.$, and $U_{i}$ ) and load information (average load and number of customers) are the same as the provided data of RBTS Bus 2. Each DG source is considered as a lumped generation unit and owns the capacity of $3 \mathrm{MW}$ that is large enough to be used as backup generation. For cases (1) to (3), all DG sources are initially assumed to be installed in front of PCCs parallel at all buses along each main feeder, i.e. buses 2, 3, $4,5,20,21,24,25,26,27,40,41,42$, and 43. The protection setting and the threshold capacity of DG installation are derived on the basis of mathematical equations of breaker, recloser, and fuse ${ }^{(7)(8)}$.

7.1 Results of Cases ( 1 ), ( 2 ), and ( 3 ) (No Tie Line)

To begin with, the calculation starts with the N-1 contingency enumeration. Due to the limited space, the detailed calculation is not shown in this paper. The probability of miscoordination is firstly set to be 1.0 in order to show the extreme case of the reliability conflict, and later for other probability values in term of sensitivity analysis. For all cases, SAIFI, SAIDI, and ENS from permanent faults in the isolation process can be calculated by using Eqs. (14)-(16), as well as SAIFI, SAIDI, and ENS of the interruption change due to the miscoordination in case (3). By doing so, SAIFI and SAIDI of cases (1) and (2) can be directly calculated. In case ( 3 ), the total SAIFI and SAIDI can be calculated by summing the SAIFI and SAIDI from permanent faults and the SAIFI and SAIDI from the change of temporary faults to permanent interruption. Regarding ENS of cases (1) and (2), it can be calculated directly from permanent faults, whereas additional ENS must also be additionally included in cases ( 3 ) for the portion resulting from the change of interruption duration.

Table 3 shows the summary results for cases (1), (2), and ( 3 ), in which tie line is not implemented yet. In the table,

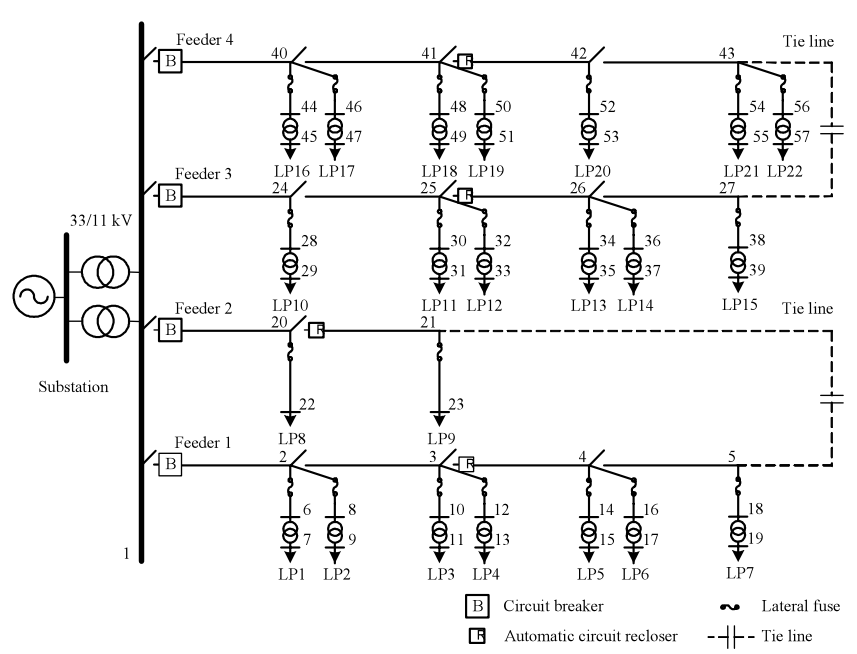

Fig. 8. The test system RBTS Bus 2 
Distribution Reliability with DG Considering Protection Miscoordination

Table 3. Comparison results of cases (1), (2), and (3)

\begin{tabular}{|c|c|c|c|c|c|c|c|c|c|c|c|c|c|c|c|c|}
\hline \multirow{2}{*}{\multicolumn{2}{|c|}{ Indices }} & \multicolumn{3}{|c|}{ Feeder 1} & \multicolumn{3}{|c|}{ Feeder 2} & \multicolumn{3}{|c|}{ Feeder 3} & \multicolumn{3}{|c|}{ Feeder 4} & \multicolumn{3}{|c|}{ Total system } \\
\hline & & Case(1) & Case(2) & \begin{tabular}{|l|} 
Case(3) \\
\end{tabular} & Case(1) & Case(2) & Case(3) & Case(1) & Case(2) & Case(3) & Case(1) & Case(2) & Case(3) & \begin{tabular}{|l|l|} 
Case(1) \\
\end{tabular} & Case(2) & Case(3) \\
\hline SAIFI-perm. & (ints/cus) & 0.1991 & 0.1991 & \begin{tabular}{|l|}
0.1991 \\
\end{tabular} & 0.1563 & 0.1563 & 0.1563 & 0.1998 & \begin{tabular}{|l|}
0.1998 \\
\end{tabular} & 0.1998 & 0.1970 & 0.1970 & 0.1970 & 0.1986 & 0.1986 & 0.1986 \\
\hline SAIDI-perm. & (hrs/cus) & 3.666 & 3.569 & 3.569 & 0.655 & 0.540 & 0.540 & 3.728 & 3.574 & 3.574 & 3.718 & 3.555 & 3.555 & 3.700 & 3.563 & 3.563 \\
\hline SAIFI-temp. & (ints/cus) & - & - & 0.2510 & - & - & 0.2080 & - & - & 0.2456 & - & - & 0.2343 & - & - & 0.2437 \\
\hline SAIDI-temp. & (hrs/cus) & - & - & 0.1255 & - & - & 0.1040 & - & - & 0.1228 & - & - & 0.1172 & - & - & 0.1219 \\
\hline ENS-perm. & (MWh) & 14.06 & 13.11 & 13.11 & 1.42 & 1.16 & 1.16 & 12.14 & 11.18 & 11.18 & 13.30 & 12.21 & 12.21 & 13.16 & 12.17 & 12.17 \\
\hline ENS-shed. & (MWh) & - & - & - & - & - & - & - & - & - & - & - & - & - & - & - \\
\hline ENS-temp. & (MWh) & - & - & 0.4569 & - & - & 0.2236 & - & - & 0.3833 & - & - & 0.4242 & - & - & 0.4216 \\
\hline Total SAIFI & (ints/cus) & 0.1991 & 0.1991 & 0.4500 & 0.1563 & 0.1563 & 0.3643 & 0.1998 & 0.1998 & 0.4454 & 0.1970 & 0.1970 & 0.4314 & 0.1986 & 0.1986 & 0.4423 \\
\hline Total SAIDI & (hrs/cus) & 3.666 & 3.569 & 3.695 & 0.655 & 0.540 & 0.644 & 3.728 & 3.574 & 3.696 & 3.718 & 3.555 & 3.672 & 3.700 & 3.563 & 3.685 \\
\hline Total ENS & (MWh) & 14.06 & 13.11 & 13.57 & 1.42 & 1.16 & 1.38 & 12.14 & 11.18 & 11.57 & 13.30 & 12.21 & 12.64 & 13.16 & 12.17 & 12.59 \\
\hline
\end{tabular}

SAIFI-perm., SAIDI-perm., and ENS-perm. result from permanent faults that is inevitable whenever faults occur. SAIFItemp., SAIDI-temp., and ENS-temp. result from the change of interruption duration when the coordination of recloser and fuses is interfered.

Comparing case (1) and case (2), it is shown that the DG installation does not reduce SAIFI. This is because the protective devices, in case (2), still need to trip and disconnect the circuit so that the faulted component can be removed safely. However, the installation of DG improves the system reliability in term of SAIDI, since it can shorten the interruption duration for the load points located out of the faulted area by getting supplied from DG. Consequently, ENS is reduced. Note that case (2) is assumed that there is no miscoordination between recloser and fuse. The purpose is to show the expected reliability improvement. In practice, as an effective but costly solution, this is possible in the case that all protective devices have a new setting or replacement subject to the contribution of DG fault current.

In case ( 3 ), where the recloser-fuse coordination is interfered, SAIFI-perm. still equals to those of cases (1) and (2) due to the same operation of protective devices to isolate the faulted component. Although, SAIDI-perm. is better as same as that of case (2), the change of interruption duration is considered in this case and the system will additionally experience SAIFI-temp. and SAIDI-temp. Since temporary faults take place in distribution system far more frequently than permanent faults, the total SAIFI is severely increased as shown. Regarding ENS, the change of interruption duration leads to the additional ENS and certainly affects the total ENS as well. From the results, it can be concluded for this radial test system that the system reliability is certainly improved with DG installation while recloser-fuse miscoordination is neglected (case (2)). In contrast, the system SAIFI becomes severely worse when recloser-fuse miscoordination is taken into account, whereas the system SAIDI and ENS can still be improved (case (3)). These confirm the fact that DG has both pros and cons to the system reliability.

In another application, the size of DG can be limited to ensure that the problem of recloser-fuse miscoordination will never happen. From section 3, the maximum fault current from DG can be calculated with the association of the existing protective devices. By using the equation of short circuit capacity, the maximum or threshold capacity of the total DG can be known. From the calculation, this threshold size of
Table 4. Results with the installation of DG at threshold size

\begin{tabular}{|c|c|c|c|c|c|c|}
\hline \multicolumn{2}{|c|}{ Indices } & Feeder 1 & Feeder 2 & Feeder 3 & Feeder 4 & Total system \\
\hline SAIFI-perm. & (ints/cus) & 0.1991 & 0.1563 & 0.1998 & 0.1970 & 0.1986 \\
\hline SAIDI-perm. & (hrs/cus) & 3.569 & 0.540 & 3.574 & 3.555 & 3.563 \\
\hline AIFI-temp. & (ints/cus) & - & - & - & - & - \\
\hline SAIDI-temp. & (hrs/cus) & - & - & - & - & - \\
\hline ENS-perm. & (MWh) & 13.11 & 1.16 & 11.18 & 12.21 & 12.17 \\
\hline ENS-shed. & (MWh) & 0.44 & 0.01 & 0.46 & 0.57 & 0.49 \\
\hline ENS-temp. & (MWh) & - & - & - & - & - \\
\hline Total SAIFI & (ints/cus) & 0.1991 & 0.1563 & 0.1998 & 0.1970 & 0.1986 \\
\hline Total SAIDI & (hrs/cus) & 3.569 & 0.540 & 3.574 & 3.555 & 3.563 \\
\hline Total ENS & (MWh) & 13.56 & 1.17 & 11.64 & 12.78 & 12.66 \\
\hline
\end{tabular}

DG is approximately $1.79 \mathrm{MW}$ for each feeder. The exact value for the total DG is slightly different corresponding to their particular characteristics. Table 4 shows that the reliability is improved from the system without the installation of DG in case (1), and certainly the reliability is worse than case (2). Comparing with case (3), the system reliability is improved in terms of SAIFI and SAIDI. However, the reliability is degraded in term of ENS. This is because some loads must be shed in the isolated area due to the limited DG capacity. As shown in Table 3, there is no ENS-shed in any case.

One may wonder what is the optimum level of DG capacity. This is still a question that needs to be clarified. Thus, a sensitivity study is conducted to analyze this issue. The result from Table 3 and Table 4 are assumed that the probability of miscoordination is 1.00 , which is the worst case. The following sensitivity study is conducted for five values of the miscoordination probability, i.e. $0.00,0.25,0.50,0.75$, and 1.00. The sensitivity is conducted by changing the total size of DG sources with the same proportion of each lumped DG source. Since the protection threshold of a feeder is different from those of other feeders. The sensitivity study is separately shown only for feeder 1 as an example. The total DG capacity starts from 0.0 MW to $4.5 \mathrm{MW}$. As mentioned, the installation of DG will improve the system reliability in term of SAIDI and ENS. It can be seen from Fig. 9 that SAIDI is reduced to 3.569 hours/customer, whereas ENS is reduced until DG matches the demand of the connecting load. In other word, ENS is getting better until the size of overall DG is more than the load and loss in the isolated area of each contingency case. However, the threshold of recloser-fuse miscoordination is $1.79 \mathrm{MW}$. This means that the miscoordination will take place when the total DG capacity is greater than 


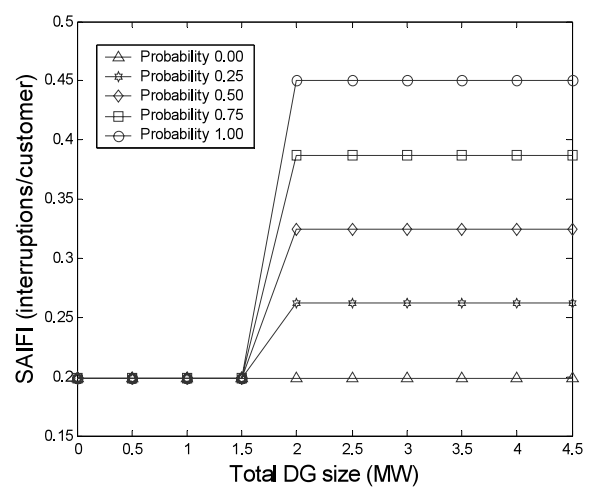

(a)

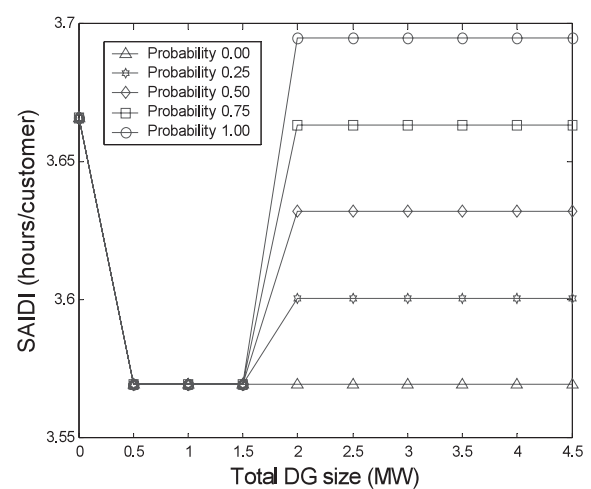

(b)

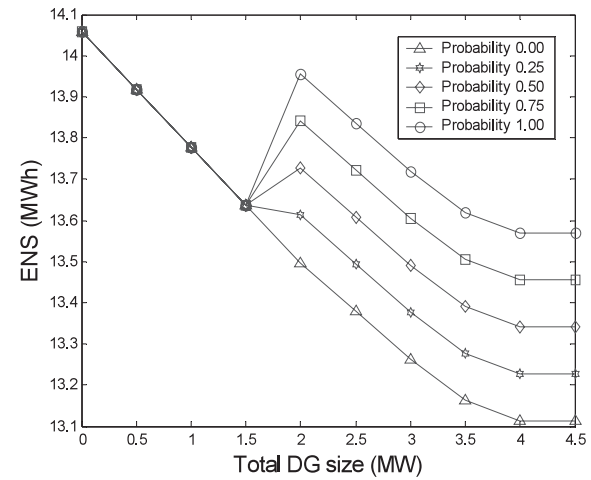

(c)

Fig. 9. Reliability indices of feeder 1 associated with change of total DG capacity: (a) SAIFI; (b) SAIDI; and (c) ENS

1.79 MW. Therefore, SAIFI, SAIDI, and ENS are distinctly degraded when the total DG capacity steps from 1.5 MW to $2 \mathrm{MW}$. After this reliability deterioration, all reliability indices keep maintaining their actual response to the increase of the total DG capacity. On the account of miscoordination probability, it is obvious that the higher the miscoordination probability is, the worse the reliability indices are. In practice, the miscoordination probability should be very low so that the advantage of DG can be fully extracted. However, this depends on the standard regulations, which are different among power distribution systems, and the compliance from DG owners with such regulations. In addition, the failure of DG-side protective devices is also an underlying factor of the problem.

Regarding the breaker-breaker miscoordination, this kind protection loss impacts wide area of electricity consumption. From Fig. 8, all loads along a feeder can be affected if this

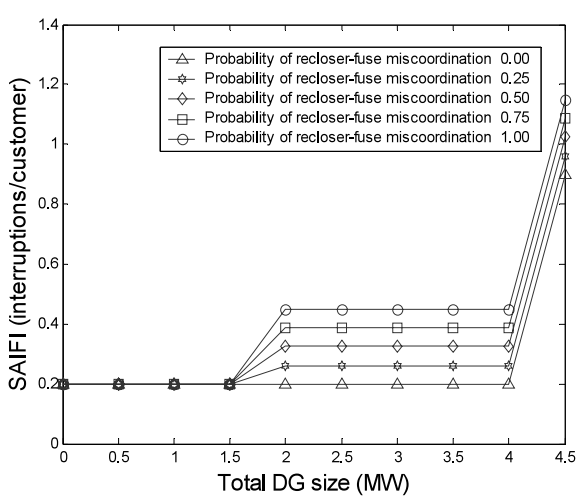

Fig. 10. SAIFI of feeder 1 associated with change of total DG capacity considering the impact of breaker-breaker miscoordination

healthy feeder is connected with large DG. However, the system operator or the utility authority can reclose the breaker and bring this healthy feeder back to normal condition within a short time. It seems that this does not cause anything worse to the system reliability. This short interruption duration is varied subject to the time used to reclose the breaker. If the breaker can be reclosed within a very short duration, such interruption may be considered as momentary interruption that can be evaluated by other related reliability indices, for example MAIFI (Momentary Average Interruption Frequency Index). In contrast, if the breaker is manually operated or is located far from the personnel in charge, this interruption may take time long enough to be considered as a normal sustained interruption. In this paper, this kind of interruption is directly combined together with the normal SAIFI. This is based on the assumption that breaker cannot be reclosed instantaneously. Besides, the worst case of breaker-breaker miscoordination can be revealed. However, this interruption duration is still not long enough to affect SAIDI and ENS. In this study, the probability of breaker-breaker miscoordination is also set to be 1.00. Fig. 10 shows that the SAIFI of feeder 1 rises up sharply when the size of total DG steps from 4.0 MW to 4.5 MW. This is because the threshold DG capacity of breaker-breaker miscoordination is $4.21 \mathrm{MW}$ in case of this feeder. This is corresponding to what mentioned in section 3 that the breaker-breaker miscoordination will occur only when large DG is installed into the system.

7.2 Results of Case (4) (with tie line) As mentioned in section 6.4, DG is less useful in case that the distribution feeder is tied to another feeder or an adjacent substation. In addition, DG can interfere the protection system and cause the worse reliability. However, DG is still beneficial to system reliability if the probability of miscoordination is low or the DG size is not too large. This section shows the advantage of on-site DG installed behind PCCs that can supply the local loads. This lumped DG source is set to be small enough not to cause the problem of miscoordination. The reliability results are studied for feeder 1 , which is tied together with feeder 2. The interested load point is LP7 at bus 5 and DG is installed behind its PCC at bus 18 in Fig. 8 .

Table 5 shows that the feeder reliability is improved by DG even the system has a tie line. The improvement is higher when the size of DG is increased. In this study, the value 
Table 5. Results of feeder 1 with tie line and small DG

\begin{tabular}{ll|r|r|r}
\hline \multicolumn{1}{c|}{ Indices } & & Without DG & DG 0.2 MW & DG 1.0 MW \\
\hline Feeder SAIFI & (ints/cus) & 0.1991 & 0.1991 & 0.1991 \\
\hline Feeder SAIDI & (hrs/cus) & 3.569 & 3.566 & 3.566 \\
\hline Feeder ENS & (MWh) & 13.11 & 13.07 & 13.02 \\
\hline Load point SAIFI & (ints/cus) & 0.2883 & 0.2883 & 0.2883 \\
\hline Load point SAIDI & (hrs/cus) & 3.637 & 3.429 & 3.429 \\
\hline Load point ENS & $(\mathrm{MWh})$ & 1.65 & 1.61 & 1.56 \\
\hline Feeder SAIDI reduction & $(\%)$ & - & 0.09 & 0.09 \\
\hline Feeder ENS reduction & $(\%)$ & - & 0.32 & 0.72 \\
\hline Local SAIDI reduction & $(\%)$ & - & 5.72 & 5.72 \\
\hline Local ENS reduction & $(\%)$ & - & 2.52 & 5.72 \\
\hline
\end{tabular}

of DG 1.0 MW is conducted as an example that the DG is large enough to supply the load at LP7 whose local load is $0.454 \mathrm{MW}$. Although the improvement is a small portion to the overall feeder reliability, this local improvement yields a remarkable notice in percent for its own reliability level. This would certainly satisfy the owners of DG who consume electricity at LP7. Furthermore, this lumped DG source can help increasing the voltage profile, when a fault occurs at the main feeder and the load is supplied from the tie line.

\section{Conclusion}

As backup generation, DG is expected to improve distribution reliability, but DG itself may cause the loss of protection coordination. With the protection miscoordination, distribution reliability may become worse than systems without DG installation. An intensive investigation has been analyzed. The numerical examples show that DG has both pros and cons to the system reliability. In addition, the numerical examples can be used further as an applicable, effective study of how to make use of DG for its ability to improve the distribution reliability of a particular system.

(Manuscript received Dec. 26, 2005, revised May 2, 2006)

\section{References}

( 1 ) W. El-Khattam and M.M.A. Salama: "Distributed generation technologies, definitions and benefits", Electric Power Systems Research, Vol.71, pp.119128 (2004-10)

( 2 ) N. Jenkins, R. Allan, P. Crossley, D. Kirschen, and G. Strbac: Embedded generation, The Institute of Technical Engineering, London (2000)

( 3 ) H.L. Willis and W.G. Scott: Distributed Power Generation, Marcel Dekker Inc, New York (2000)

( 4 ) Y. Li, D.M. Vilathgamuwa, and P.C. Loh: "Design, analysis, and real-time testing of a controller for multibus microgrid system", IEEE Trans. Power Electronics, Vol.19, pp.1195-1204 (2004-9)

( 5 ) S. Barsali, M. Ceraolo, P. Pelacchi, and D. Poli: "Control techniques of dispersed generators to improve the continuity of electricity supply", Proc. 2002 IEEE Power Engineering Society Winter Meeting Conf., pp.789-794 (2002)
( 6 ) IEEE Recommended Practice for Utility Interface of Photovoltaic (PV) System, IEEE Standard 929-2000 (2002-4)

( 7 ) S. Chaitusaney and A. Yokoyama: "An appropriate distributed generation sizing considering recloser-fuse coordination", Proc. 2005 IEEE Power Engineering Society Transmission and Distribution Conference and Exhibition Conf., pp.1-6 (2005-8)

( 8 ) S. Chaitusaney and A. Yokoyama: "Impact of protection coordination on sizes of several distributed generation sources", Proc. 2005 The 17th International Power Engineering Conference (IPEC2005) Conf. (2005-11)

( 9 ) V. John, Z. Ye, and A. Kolwalkar: "Investigation of anti-islanding protection of power converter based distributed generators using frequency domain analysis", IEEE Trans. Power Electronics, Vol.19, pp.1177-1183 (2004-9)

(10) S. Chaitusaney and A. Yokoyama: "Conflict between Backup Generation and Recloser-fuse Miscoordination in Reliability Aspect from Distributed Generation", Proc. 2006 The IASTED International Conference on Energy and Power Systems Conf. (2006-3)

(11) J.L. Blackburn: Protective Relaying, Principles and Applications, Marcel Dekker Inc, New York (1998)

(12) R. Billinton and R.N. Allan: Reliability Evaluation of Power System, Pitman Publishing Inc, Massachusetts (1984)

(13) IEEE Standard Inverse-Time Characteristic Equations for Overcurrent Relays, IEEE Standard C37.112-1996 (1996-9)

(14) E.N. Dialynas and M.P. Papadopoulos: "Reliability assessment studies in distribution network operation and planning", Proc. 1989 The $10^{\text {th }}$ International Conference on Electricity Distribution (CIRED1989) Conf., pp.568$572(1989-5)$

(15) A. Girgis and S. Brahma: "Effect of distributed generation on protective device coordination in distribution system", Proc. 2001 Large Engineering Systems Conference on Power Engineering (LESCOPE2001) Conf., pp.115-119 (2001-7)

(16) IEEE Guide for Interfacing Dispersed Storage and Generation Facilities with Electric Utility Systems, IEEE Standard 1001-1988 (1989-4)

(17) IEEE Standard for Interconnecting Distributed Resources with Electric Power Systems, IEEE Standard 1547-2003 (2003-7)

(18) R.N. Allan, R. Billinton, I. Sjarief, L. Goel, and K.S. So: "A reliability test system for educational purposes - basic distribution system data and results", IEEE Trans. Power Systems, Vol.6, pp.813-820 (1991-5)

Surachai Chaitusaney (Student Member) received the B.Eng. and

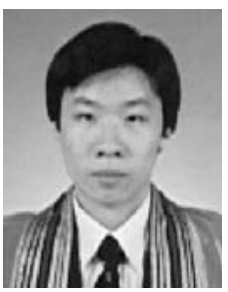
M.Eng. in Electrical Engineering, Chulalongkorn University, Thailand, in 2000 and 2002 respectively. From 2002 to 2004, he worked at Energy Research Institute and Center of Excellence in Power Technology, Chulalongkorn University. He is currently pursuing the Ph.D. degree at the University of Tokyo, Japan, with JICA scholarship. His interests include distributed generation and system reliability.

Akihiko Yokoyama (Member) was born in Osaka, Japan, on Octo-

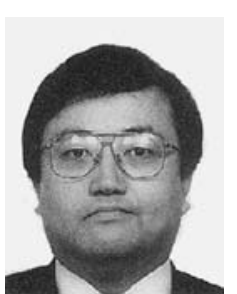
ber 9, 1956. He received B.S., M.S. and Dr. Eng from The University of Tokyo, Tokyo, Japan in 1979, 1981 and 1984, respectively. He has been with Department of Electrical Engineering, The University of Tokyo since 1984 and currently a professor in charge of Power System Engineering. He is a member of IEEJ, IEEE and CIGRE. 